\title{
Electrolyte influence on sorption behaviours of Direct Blue 71 dye on ramie fibre
}

\author{
Chi Yuan ${ }^{1}$, Kankan Lou ${ }^{1,2}$, Liping Yư ${ }^{3}$, Md. Nahid Pervez ${ }^{4}$, Siwei Su ${ }^{1}$, Jun Huang ${ }^{2}$, Xiongyi Peng ${ }^{2}$ and Yingjie Cai ${ }^{1,2,5}$ \\ ${ }^{1}$ School of Chemistry and Chemical Engineering, Wuhan Textile University, Wuhan 430073, China \\ ${ }^{2}$ Hubei Provincial Engineering Laboratory for Clean Production and High Value Utilization of Bio-based Textile Materials, Wuhan Textile \\ University, Wuhan 430073, China \\ ${ }^{3} Z$ hejiang Institute of Modern Textile Industry, Shaoxing 312000, China \\ ${ }^{4}$ Research institute of flexible materials, School of Textiles \& Design, Heriot-Watt University, Galashiels TD1 3HF, UK \\ ${ }^{5}$ Engineering Research Centre for Clean Production of Textile Dyeing and Printing, Ministry of Education, Wuhan Textile University, Wuhan, \\ 430073, China
}

\begin{abstract}
Ramie loose fibre was dyed using Direct Blue 71 dye at $70,80,90$ and $100^{\circ} \mathrm{C}$ without and with $\mathrm{NaCl}$ electrolyte in order to investigate the distinction of dye sorption behaviours. The results show that the dye exhaustion increases with addition of $\mathrm{NaCl}$ and shortens the equilibrium dyeing time. The dye adsorption process of dyeing without and with $\mathrm{NaCl}$ followed pseudo second-order kinetics, but the rate constant of sorption is larger for the latter compared to the former.
\end{abstract}

\section{Introduction}

Cellulose is the most abundant biopolymer and of specific interest in accoutrement renewable, sustainable, biodegradable biopolymers for automated applications. Cellulose is a linear 1,4 - $\beta$-glucan polymer where the units are able to form rather ordered systems, this occurs as a result of sizable interplay through intra- and intermolecular hydrogen bonding of the three hydroxyl corporations in each cellulose assemblage [1]. Ramie ranks as an archetypal fibre in that it has been acclimated in abounding countries since time immemorial, aswell accepted as "China grass,". It is the longest, most powerful and maximum notably orientated cellulosic fibre; appropriately degummed and bleached fibre is nearly natural cellulose, like cotton, and includes approximately high percentage of cellulose $(65-75 \%)$ and low proportion of lignin (1-2\%) in comparison with wood (40-50\% of cellulose and 15-35\% of lignin) [2-5]. Earlier advisers [6] have in comparison the size and shape of ramie, flax, and cotton fibers and accept approved that the adjustment of cross-sectional size among the three fibers is ramie $>$ flax $>$ cotton. Ramie fabrics address warmth, take in moisture and have better resistance to mould than other cellulosic fibers. Ramie is an abiding plant. The stems grow from rhizomes and are harvested five years afterwards planting. The plants can yield fibre for 30 years and can be harvested three times a year. There has been an incredible deal of interest inside the studies and utilisation of ramie in contempo years [79].
Direct dyes are about inexpensive, simple to apply, and accessible in a full ambit of shades. They are aswell tinctorially stronger than different cellulose dyes, and very dark shades can be acquired economically with low dye concentrations. Furthermore, a few direct dyes have excellent light fastness [10]. Direct dyes are accepted in dyeing of cellulosic fibres due to its anionic and water soluble (sodium salts of sulfonic acids) attributes [11]. Differences from the covalent bonds of reactive dyeing on cellulose, direct dyes are loosely associated with cellulosic substance by substantivity including the Van der Waals forces and hydrogen bonds. It is aswell believed that cellulosic fibers access a negative charge when immersed in aqueous media due to their decreased dielectric constant connected with that of water and that this has the aftereffect of against the analogously charged ion of the substantive dye. But it is claimed that electrolytes have a tendency to abate or extinguish the allegation on the fiber, appropriately facilitating an alteration of dye from. Earlier workers had explained the aftereffect of electrolytes on the base of an abatement in the abrogating apparent abeyant of the fiber [12-14].

Water pollution has apparently influenced on the sustainable development of textile industries, owing to an increase of the cost for treating the waste water before discharging. In order to obtain high dye exhaustion, normally, increase of dyeing temperature or addition of electrolyte is widely applied, and both operations alter the dye sorption behaviours during dyeing [15].

Therefore, this paper aims to discover the distinction of dye sorption behaviours under varying dyeing temperatures with or without electrolyte addition, and this 
achievement potentially assists the dyeing plants to seek a suitable dyeing profile for direct dyeing of cellulosic fibre.

\section{Experimental}

\subsection{Materials}

Ramie loose fibre was obtained from Hunan Huasheng Zhuzhou Cedar Company, China. Direct Blue 71 dye (commercial grade), was purchased from the Shanghai Jiaying Chemical Company, China and utilized directly without purification, which molecular structure is shown in Figure 1. Sodium chloride (electrolyte, 99.5\%) was supplied from the Sinopharm Chemical Reagent Company, China.

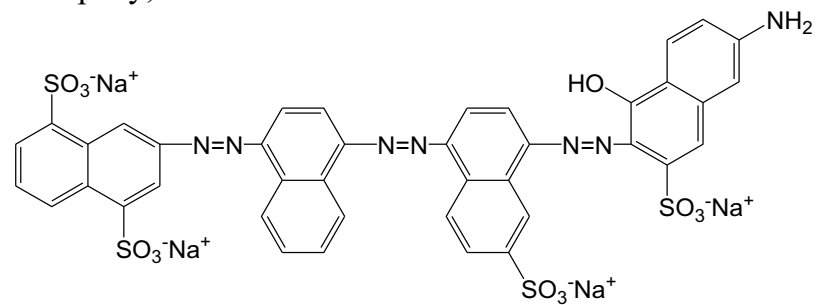

Figure 1. Molecular structure of Direct Blue 71 dyestaff

\subsection{Procedures}

The ramie loosely fibre was dyed with $3 \%$ dye o.m.f at a liquor ratio of $50: 1$ at $70,80,90$, and $100^{\circ} \mathrm{C}$ in a shaker dyeing machine (HB-24, Huibao Ranzheng Jixie Company, China). The dye bath was heated to the desired temperature $\left(70,80,90\right.$, and $\left.100^{\circ} \mathrm{C}\right)$, subsequently ramie loosely fibre was immersed in the dye bath. After $15 \mathrm{~min}$, $\mathrm{NaCl}$ of $30 \mathrm{~g} \mathrm{~L}^{-1}$ was added in, and dyeing was conducted until dye absorption equilibrium.

\subsection{Measurement}

The dye exhaustion percentage $(\% \mathrm{E})$ is the ratio of the amount of dye adsorbed by a fiber after dyeing with the initial amount of dye. The light absorbance of dye bath for different dyeing time was measured using an UV/visible spectrophoto-meter, (UV1100, Beijing Rayleigh analytical instrument Corp., China) at the wavelength of maximum absorbance $(570 \mathrm{~nm}$ for Direct Blue 71). The dye exhaustion rates for varying dyeing time were calculated by Equation 1 .

$$
E \%=\frac{A_{0}-A_{t}}{A_{0}} \times 100 \%
$$

Where $\mathrm{E} \%$ is the dye exhaustion rate, $\mathrm{A}_{0}$ and $\mathrm{A}_{\mathrm{t}}$ are the light absorbency values of the dye bath before and after dyeing respectively.

The amount of adsorbed dye per unit mass of substrate, $[\mathrm{D}]_{\mathrm{f}}\left(\mathrm{g} \mathrm{g}^{-1}\right)$, was calculated using Equation 2.

$$
[D]_{f}=\frac{E \% \times M_{d}}{M_{f}}=E \% \times \text { o.m.f } \%
$$

Where $\mathrm{M}_{\mathrm{d}}(\mathrm{g})$ is the mass of dye used in dyeing, $\mathrm{M}_{\mathrm{f}}(\mathrm{g})$ is the mass of ramie loosely fibre, o.m.f\% is the value that dye quantity on the mass of fibre, which is $3 \%$ in this research work.

\section{Results and discussion}

The dyeing exhaustion rates of Direct Blue 71 on ramie loose fibre without and with addition of $\mathrm{NaCl}$ are displayed in Figure 2. For dyeing temperature at 70 to $100^{\circ} \mathrm{C}$, the dye exhaustion rates for without addition of $\mathrm{NaCl}$, the values are similar, which are within 60 to $65 \%$; while for addition of salt, that are in the range of 80 to $94 \%$. It is interesting that both the exhaustion rates for without and with addition of $\mathrm{NaCl}$ at $100^{\circ} \mathrm{C}$ are the lowest one among the dyeing temperatures. It is possible that during dyeing, the dye exhaustion is a reversible process due its physical sorption, thus at high temperature, the desorption rate is higher than at low temperature thereof the better colour uniformity for dyed substance.

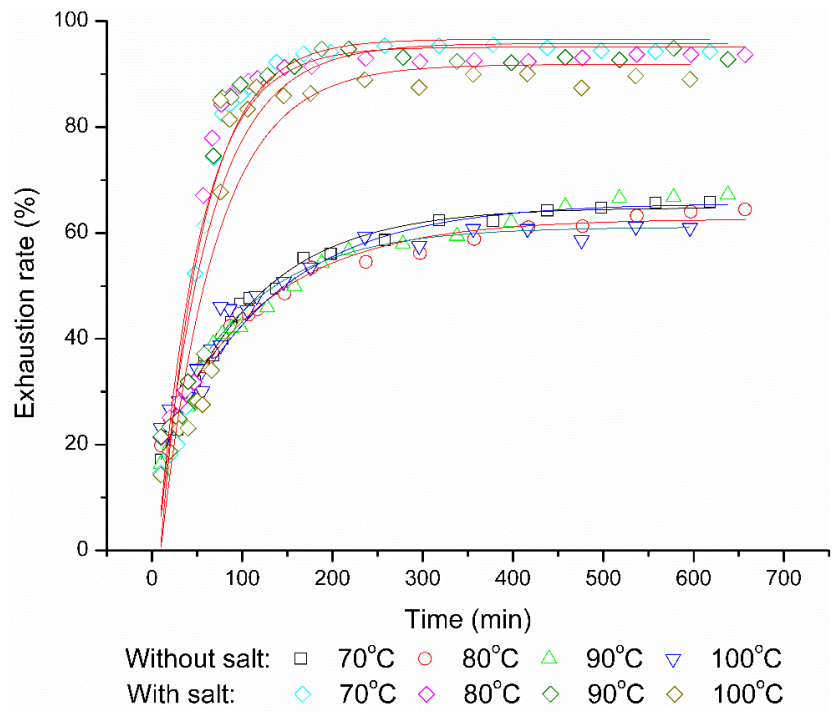

Figure 2. Exhaustion rates of Direct Blue 71 without and with addition of $\mathrm{NaCl}$

As mention above, direct dyes were adsorbed on substance by substantivity, which can be calculated by Equation $3[16,17]$. It represents the relationship between substantivity, liquor ratio, and the percentage of exhaustion at equilibrium.

$$
K=\frac{\% E_{e} \times L}{100-\% E_{e}}
$$

Where $\mathrm{K}$ is the substantivity of dye; $\% \mathrm{E}_{\mathrm{e}}$ is the percentage of exhaustion at equilibrium; and $\mathrm{L}$ is the liquor ratio.

The $\mathrm{K}$ value indicates the efficiency of dye transferred from the dye bath to the substrate. A greater value of $\mathrm{K}$ means that the dye is favored to stay in the fiber. Table 1 shows the $\mathrm{K}$ values of dyeing with addition of $\mathrm{NaCl}$ are greater than those of without addition. Therefore, it could be concluded that addition of $\mathrm{NaCl}$ is an effective method to promote dye exhaustion in direct dyeing. It is apparently shown that dyeing at $90^{\circ} \mathrm{C}$ in with 
or without addition of salt, it has the highest exhaustion thereof the highest substantivity.

Table 1. Substantivity values of different dyeing conditions

\begin{tabular}{|l|l|l|l|l|l|}
\hline \multirow{2}{*}{ Temperature $\left({ }^{\circ} \mathrm{C}\right)$} & \multirow{2}{*}{$\mathrm{L}$} & \multicolumn{2}{|c|}{ Without $\mathrm{NaCl}$} & \multicolumn{2}{l|}{ With $\mathrm{NaCl}$} \\
\cline { 3 - 6 } & & $\% \mathrm{E}_{\mathrm{e}}{ }^{*}$ & $\mathrm{~K}$ & $\% \mathrm{E}_{\mathrm{e}}{ }^{*}$ & $\mathrm{~K}$ \\
\hline 70 & 50 & 64.7 & 91.6 & 95.8 & 1140.8 \\
\hline 80 & 50 & 62.5 & 83.3 & 91.8 & 562.2 \\
\hline 90 & 50 & 65.4 & 94.4 & 96.6 & 1419.0 \\
\hline 100 & 50 & 61.0 & 78.2 & 95.1 & 970.6 \\
\hline
\end{tabular}

In direct dyeing process, kinetic model analyse is assistant to interpret the dynamic interaction between ramie fibre and the direct dyes, which normally uses pseudo first-order model and pseudo second-order model $[18,19]$ to predict the sorption mechanism. The pseudo first- and second-order model can be expressed by Equation 4 and Equation 5.

$$
\log \left([D]_{f, e}-[D]_{f, t}\right)=\log [D]_{f, e}-\frac{K_{1}}{2.3} t
$$

Where $\mathrm{k}_{1}$ is the pseudo first-order rate constant $\left(\mathrm{s}^{-1}\right)$ of adsorption; $[\mathrm{D}]_{\mathrm{f}, \mathrm{e}}$ and $[\mathrm{D}]_{\mathrm{f}, \mathrm{t}}\left(\mathrm{g} \mathrm{g}^{-1}\right)$ are the amounts of dye adsorbed per unit mass of ramie yarn at equilibrium and time $\mathrm{t}(\mathrm{s})$, respectively. The value of $\log \left([\mathrm{D}]_{\mathrm{f}, \mathrm{e}}-[\mathrm{D}]_{\mathrm{f}, \mathrm{t}}\right)$ can be calculated from the experimental results and plotted against $\mathrm{t}(\mathrm{s})$.

$$
\frac{t}{[D]_{f, t}}=\frac{1}{K_{2}[D]_{f, e}{ }^{2}}+\frac{t}{[D]_{f, e}}
$$

Where $\mathrm{K}_{2}$ is the pseudo second-order rate constant of adsorption $\left(\mathrm{g} \mathrm{g}^{-1}\right)$. The slope and intercept of the linear plot $t /[D]_{f, t}$ Vs. $t$ yield the values of $[D]_{f, e}$ and $k_{2}$.

The plots of the pseudo second-order with both dyeing conditions are displayed in Figure 3, which apparently shows that the value of $t /[D]_{f, t}$ are sharply dropped after addition of $\mathrm{NaCl}$. However, the dye sorption of kinetic model does not change, which still fits the pseudo second-order, and the $\mathrm{K}_{2}$ values are larger with addition of $\mathrm{NaCl}$ than that without addition of $\mathrm{NaCl}$. The experimental and calculated $[\mathrm{D}]_{\mathrm{f}, \mathrm{e}}$ values, pseudo second-order rate constants, and regression coefficient $\left(\mathrm{R}^{2}\right)$ values are listed in Table 2 , and the data for addition of salt are after addition of $\mathrm{NaCl}$.

Table 2 and Table 3 show that for adsorption of both dyeing conditions, the correlation coefficients of the pseudo second-order model are better than that of the pseudo first-order model. The better correlation between the equilibrium adsorption capacities of calculation $\left([\mathrm{D}]_{\mathrm{f}, \mathrm{e}}\right.$, cal.) and the experimental values $\left([\mathrm{D}]_{\mathrm{f}, \mathrm{e}}\right.$, exp.) implies that the pseudo second-order model is more likely to represent the adsorption kinetics of both dyeing conditions.

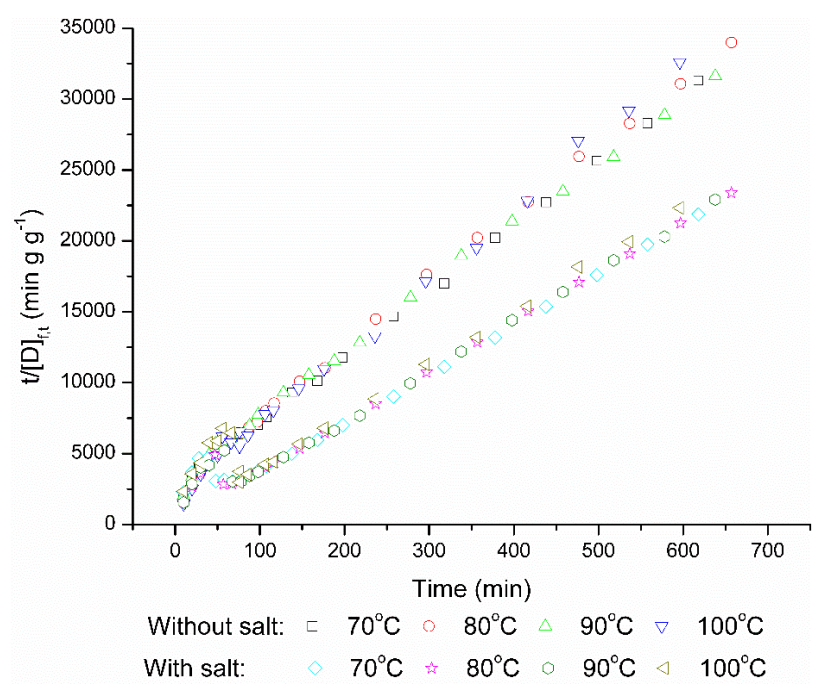

Figure 3. Plots of pseudo second-order without and with addition of $\mathrm{NaCl}$

The direct dyeing process was a solid/liquid phase process, which proceeded by the diffusion of the dye molecule through the dye bath (liquid phase) to the ramie fibre (solid surface) as a result of the affinity of the two, followed by the dye diffusion into the fibre. As a result, the first solution diffusion process would be swift and the second diffusion process into the solid fibre would be slow.

Table 2. Kinetic parameters of pseudo first-order for

\begin{tabular}{|c|c|c|c|c|c|}
\hline Conditions & $\begin{array}{l}\text { Temp. } \\
\left({ }^{\circ} \mathrm{C}\right)\end{array}$ & $\begin{array}{l}{[\mathrm{D}]_{\mathrm{f}, \mathrm{e}}} \\
(\exp )(\mathrm{g} \\
\left.\mathrm{g}^{-1}\right)\end{array}$ & $\begin{array}{l}\mathrm{K}_{1}\left(\mathrm{~s}^{-}\right. \\
1)\end{array}$ & $\begin{array}{l}{[\mathrm{D}]_{\mathrm{f}, \mathrm{e}}} \\
(\mathrm{cal})(\mathrm{g} \\
\left.\mathrm{g}^{-1}\right)\end{array}$ & $\mathrm{R}^{2}{ }_{1}$ \\
\hline \multirow{4}{*}{$\begin{array}{l}\text { Without } \\
\mathrm{NaCl}\end{array}$} & 70 & 0.0194 & 0.0097 & 0.0157 & 0.9702 \\
\hline & 80 & 0.0188 & 0.0074 & 0.0125 & 0.9830 \\
\hline & 90 & 0.0196 & 0.0085 & 0.0165 & 0.9035 \\
\hline & 100 & 0.0183 & 0.0108 & 0.0132 & 0.8723 \\
\hline \multirow{4}{*}{ With $\mathrm{NaCl}$} & 70 & 0.0287 & 0.0076 & 0.0084 & 0.6063 \\
\hline & 80 & 0.0276 & 0.0359 & 0.0486 & 0.9666 \\
\hline & 90 & 0.0290 & 0.0051 & 0.0090 & 0.5388 \\
\hline & 100 & 0.0285 & 0.0044 & 0.0119 & 0.5597 \\
\hline
\end{tabular}
adsorption of dyes on ramie yarns

Half-dyeing time $\left(\mathrm{t}_{1 / 2}\right)$ is the time that $50 \%$ of the dye amount adsorbed at equilibrium by fiber. It can indirectly express the diffusion rate of dye in a fiber and is used to compare the behavior of dyes applied under the same dyeing conditions. The half-dyeing time of the different dyeing conditions, as listed in Table 4 , were calculated using Equation 6 based on Equation $5\left(\mathrm{t}=\mathrm{t}_{1 / 2},[\mathrm{D}]_{\mathrm{f}, \mathrm{t}}=[\mathrm{D}]_{\mathrm{f}, \mathrm{e}}\right.$ /2).

$$
t_{1 / 2}=\frac{1}{K_{2} \times[D]_{f, e}}
$$


Table 3. Kinetic parameters of pseudo second-order for adsorption of dyes on ramie yarns

\begin{tabular}{|c|c|c|c|c|c|}
\hline \multirow{3}{*}{ Conditions } & $\begin{array}{l}\text { Temp. } \\
\left({ }^{\circ} \mathrm{C}\right)\end{array}$ & $\begin{array}{l}{[\mathrm{D}]_{\mathrm{f}, \mathrm{e}}} \\
(\mathrm{exp})(\mathrm{g} \\
\left.\mathrm{g}^{-1}\right)\end{array}$ & $\begin{array}{l}\mathrm{K}_{2}\left(\mathrm{~g} \mathrm{~g}^{-}\right. \\
\left.\mathrm{s}^{-1}\right)\end{array}$ & $\begin{array}{l}{[\mathrm{D}]_{\mathrm{fe}}} \\
(\mathrm{cal}) \\
\left.\mathrm{g}^{-1}\right)\end{array}$ & $\mathrm{R}^{2}{ }^{2}$ \\
\hline \multirow{3}{*}{$\begin{array}{c}\text { Without } \\
\mathrm{NaCl}\end{array}$} & 70 & 0.0194 & 0.8486 & 0.0215 & 0.9987 \\
\cline { 2 - 6 } & 80 & 0.0188 & 0.9409 & 0.0206 & 0.9978 \\
\cline { 2 - 6 } & 90 & 0.0196 & 0.6971 & 0.0221 & 0.9973 \\
\cline { 2 - 6 } With $\mathrm{NaCl}$ & 100 & 0.0183 & 1.2424 & 0.0197 & 0.9964 \\
\cline { 2 - 6 } & 80 & 0.0287 & 1.9123 & 0.0295 & 0.9973 \\
\cline { 2 - 6 } & 90 & 0.0276 & 3.2050 & 0.0286 & 0.9996 \\
\cline { 2 - 6 } & 100 & 0.0285 & 3.7138 & 0.0273 & 0.9988 \\
\hline
\end{tabular}

Table 4. Half-dyeing times and diffusion coefficients

\begin{tabular}{|l|c|c|c|c|c|}
\hline Conditions & $\begin{array}{c}\text { Temp. } \\
\left({ }^{\circ} \mathrm{C}\right)\end{array}$ & $\begin{array}{c}\mathrm{K}_{2}\left(\mathrm{~g} \mathrm{~g}^{-}\right. \\
\left.\mathrm{s}^{-1}\right)\end{array}$ & $\begin{array}{c}{[\mathrm{D}]_{\mathrm{f}, \mathrm{e}}} \\
(\mathrm{cal}) \\
\left(\mathrm{g} \mathrm{g}^{-1}\right)\end{array}$ & $\begin{array}{c}\mathrm{t}_{1 / 2} \\
(\mathrm{~s})\end{array}$ & $\begin{array}{c}\mathrm{D}\left(\times 10^{-10}\right. \\
\left.\mathrm{m}^{2} \mathrm{~min}^{-1}\right)\end{array}$ \\
\hline \multirow{4}{*}{$\begin{array}{l}\text { Without } \\
\mathrm{NaCl}\end{array}$} & 70 & 0.6475 & 0.0194 & 79.59 & 1.48 \\
\cline { 2 - 6 } & 80 & 1.6859 & 0.0187 & 31.64 & 3.72 \\
\cline { 2 - 6 } & 90 & 2.8307 & 0.0196 & 18.01 & 6.53 \\
\cline { 2 - 6 } & 100 & 7.1619 & 0.0183 & 7.63 & 15.42 \\
\hline \multirow{5}{*}{ With $\mathrm{NaCl}$} & 70 & 1.9123 & 0.0287 & 18.19 & 6.47 \\
\cline { 2 - 6 } & 80 & 3.2050 & 0.0275 & 11.33 & 10.389 \\
\cline { 2 - 6 } & 90 & 4.5646 & 0.0290 & 7.56 & 15.56 \\
\cline { 2 - 6 } & 100 & 3.7138 & 0.0285 & 9.44 & 12.47 \\
\hline
\end{tabular}

The kinetics of the adsorption of the dyes by cellulosic fibers is usually described by the Hill equation for diffusion [20]. The diffusion coefficient at half-dyeing time, as given in Table 4, was calculated using Equation 7 which was deduced from the Hill equation [19].

$$
\mathrm{D}=\left(\frac{[\mathrm{D}]_{\mathrm{f}, \mathrm{t}}}{[\mathrm{D}]_{\mathrm{f}, \mathrm{e}}}\right) \times \frac{100 \times \mathrm{d}^{2}}{\mathrm{t}}
$$

Where $\mathrm{D}\left(\mathrm{m}^{2} \mathrm{~min}^{-1}\right)$ is the diffusion coefficient at half-dyeing time; $t$ ( $\mathrm{min}$ ) is the half-dyeing time, $\mathrm{t}_{1 / 2} ; \mathrm{d}$ is the diameter of ramie fiber, $40.2 \mu \mathrm{m}$.

In Table 4, the half-dyeing time and diffusion coefficient at half-dyeing time for dyeing without $\mathrm{NaCl}$ decrease and increases with increasing of dyeing temperature respectively; and it is almost similar with the dyeing with $\mathrm{NaCl}$ excepting for the dyeing at $100^{\circ} \mathrm{C}$. At $100^{\circ} \mathrm{C}$ dyeing with $\mathrm{NaCl}$, the half-dyeing time increases from $7.56 \mathrm{~min}$ at $90^{\circ} \mathrm{C}$ to $9.44 \mathrm{~min}$ and the diffusion coefficient at half-dyeing time reduces from $15.56 \times 10^{-10}$ $\mathrm{m}^{2} \min ^{-1}$ at $90^{\circ} \mathrm{C}$ to $12.47 \times 10^{-10} \mathrm{~m}^{2} \mathrm{~min}^{-1}$.

\section{Conclusion}

Additon of $\mathrm{NaCl}$ electrolyte promotes the sorption of Direct Blue 71 on ramie loosely fibre, and shortens its equilibrium time. The dye adsorption process of dyeing without and with $\mathrm{NaCl}$ followed pseudo second-order rate kinetics, but the rate constant of sorption is larger for the latter compared to the former. Besides, in contrast with the dyeing without addition of $\mathrm{NaCl}$, the half-dyeing time and the diffusion coefficient for $t_{1 / 2}$ of dyeing with $\mathrm{NaCl}$ is shorter and higher respectively.

\section{Acknowledgement}

This work was financially supported by the China National Textile \& Apparel Council (2013 “Textile Vision" Applied Basic Research, 2013-153); Hubei Province Science and Technology Support Program (Grant No. 2013BAA043) and the Collaborative Innovation Plan of Hubei Province for Key Technology of Eco-Ramie Industry (2014-8).

\section{References}

1. D. Klemm, B. Heublein, H.P. Fink, A. Bohn, Angew. Chem. Int. Ed., 44, 3358 (2005)

2. S. N. Pandey, Textile Progress, 39, 1 (2007)

3. Z. Li, Z. Li, R. Ding, C. Yu, Textile Research Journal, 86, 451 (2016)

4. D. Fengel and X. Shao, Wood Sci. and Technol., 18, 103 (1984)

5. S. Nam, A. N. Netravali, Fibers and Polymers, 7, 372 (2006)

6. R. Thakur, C.R. Sarkar, R. Sarmah, Indian Journal of Fiber \& Textile Research, 24, 276 (1999)

7. L. Cheek, L. Roussel, Textile Research Journal, 59, 541 (1989)

8. D. Das, A.K. Samanta, P.C. Dasgupta, Indian Journal of Fiber \& Textile Research, 22, 53 (1997)

9. L. Cheek, Clothing and Textiles Research Journal, 8 38 (1990)

10. M. Kanik, P. J. Hauser. Textile research journal, 74, 43 (2004)

11. A.O. Noah, C. M. Martins, J. A. Braimah, Journal of applied polymer science, 32, 5841 (1986)

12. R. B. Chevan, J. V. Rao, Text\& Res. J., 39, 292 (1983)

13. H. F. Willis, J. O. Warwicker, H.A. Standing, A.R. Urquhart, Transactions of the Faraday Society, 45, 506 (1945)

14. G.M. Simu, S. Funar-Timofei, L. Kurunczi, Chemical Bulletin of Politehnica University of Timisoara. 53, 153 (2008)

15. J.R. Aspland, Textile Chemist \& Colorist. 23, 13 (1991)

16. C.-w. Kan, AUTEX Research Journal. 8, 255 (2007)

17. M. Razvigorova, T. Budinova, N. Petrov, V. Minkova, Water Res. 32, 2135 (1998)

18. Y.S. Ho, G. McKay, Process Biochem. 34, 451 (1999)

19. G.E. Krichevsk, I.M. Movshovich, Text Res J. 40, 793 (1970)

20. M.N. Michael, S.H. Samaha, S.F. Lbrahim, Colourage. 44, 23 (1997) 